\title{
Utilização de Problem Based Learning como Estratégia de Ensino em uma Instituição Federal de Ensino.
}

\author{
Fabricio Sobrosa Affeldt \\ IFRS -Instituto Federal do Rio Grande do Sul, Brazil
}

\begin{abstract}
Resumo
O presente trabalho propôs a superação das barreiras tradicionais com a utilização de estratégias pedagógicas para a implementação de inovações no ensino da área de Administração, utilizando-se situações de aprendizagem e problem based learning. A metodologia utilizada foi a da "pesquisa-ação". Se propôs um modelo construtivista, composto por uma metodologia de ensino e um ambiente de aprendizagem, elaborados com base no construtivismo. O modelo foi formado por "Contextos de Aprendizagem" e "Situações de Aprendizagem", baseados em problemas empresariais reais. Os resultados indicam que o modelo proposto atende aos requisitos: resolução de problemas; objetos de aprendizagem contextualizados; apoio à construção do conhecimento; apresentar condições para atividades aplicáveis à realidade; atividades resolvidas em grupos; tarefas realizadas através de problemas que reflitam situações concretas.
\end{abstract}

Palavras-chave: ensino de administração, problem based learning, estratégia de ensino, situações de aprendizagem.

\begin{abstract}
The present work purposes overcoming the barriers of traditional management education with support of learning strategies to bring innovation using learning situations and problem based learning methodology. The research method was "action research". A constructivist model for management education was proposed, based in a teaching methodology and in a learning environment, both derived from the constructivist assumptions. The model was formed by "Learning Contexts" and "Learning Situations", in which students had to solve real business problems. Research results indicate that the model meets the following requirements: problem-solving activities; learning objects based on real business contexts; support knowledge construction; contextualized activities, related to reality; group activities; problems that reflect real situations, found in real business world.
\end{abstract}

Key-words: management education, problem based learning, teaching strategy, learning situations.

\section{Introdução}

Argumenta-se que os estudantes egressos de cursos técnicos e superiores na área de gestão não são suficientemente hábeis para aplicar o conhecimento na resolução de problemas complexos em seus contextos de trabalho (GUEDES et al., 2015; MARION, 2007; GIJBELS et al., 2006). Os estudantes, em cursos ministrados de maneira tradicional, recebem grande quantidade de informações e a aplicabilidade prática fica limitada. Entretanto, na maioria das áreas de conhecimento existem iniciativas de aproximar as empresas das universidades e escolas, para que a experiência e a prática possam fazer parte dos currículos. O objetivo da mudança está na exposição dos 
estudantes a experiências práticas, durante os cursos, para que eles vivenciem situações práticas com a necessidade de tomada de decisões e resolução de problemas reais.

Este trabalho de pesquisa segue por este caminho, apresentando um Modelo de Ensino e Aprendizagem baseado em Problem Based Learning (PBL), uma estratégia de ensino baseada em problemas que os estudantes devem resolver. PBL centraliza o processo na figura do estudante, através da definição de problemas baseados na realidade, como: tomada de decisão, definição de diagnósticos e problemas relacionados à definição de políticas (JONASSEN; HUNG, 2015). O modelo utilizado na pesquisa foi criado a partir de uma metodologia de ensino e de um ambiente de aprendizagem em que os estudantes realizavam atividades, resolviam problemas e lidavam com situações práticas ligadas aos conceitos. $\mathrm{O}$ ambiente de aprendizagem foi elaborado a partir da construção de objetos de aprendizagem, delimitados em Contextos e Situações de Aprendizagem, utilizando-se PBL como estratégia de ensino.

O objetivo da pesquisa foi: propor um modelo construtivista para o ensino de Administração, composto por uma metodologia de ensino baseada em PBL e por um ambiente de aprendizagem, baseado em objetos de aprendizagem, com um conjunto de funcionalidades e um amplo espectro de aplicação que favorecesse o aprendizado do estudante. Realizou-se um diagnóstico no processo de ensino tradicional usado na instituição pesquisada e modificou-se a forma com que os estudantes aprendiam, utilizando-se a pesquisa-ação como estratégia de pesquisa, um método de pesquisa em que o pesquisador modifica os processos que estão sendo pesquisados.

\section{Fundamentação Teórica}

\subsection{Construção do Conhecimento}

A abordagem da Epistemologia Genética possui como precursor Jean Piaget, para quem o ser humano desenvolve gradualmente seu conhecimento através de um mecanismo que se regula em função da experiência e tende a chegar a um nível de possibilidades chamado hipotético-dedutivo pela especialização progressiva de suas funções. Trata-se de um processo baseado em estruturas biológicas que se desenvolvem e se completam ao chegar ao nível da criação das operações formais. Becker (2001, p. 88) ressalta: "construtivismo significa isto: a ideia de que nada, a rigor, está pronto, acabado, e de que, especificamente, o conhecimento não é dado, em nenhuma instância, como algo terminado". Assim, o processo de desenvolvimento do conhecimento humano é constante e construtivo, no sentido de que se parte de algum nível préexistente e ocorre continuamente na interação entre o sujeito e o mundo.

Macedo (1994) ressalta que a formação do conhecimento no intelecto está relacionada às estruturas biológicas que habilitam o ser humano e que se desenvolvem em termos cognitivos. Para Ramozzi-Chiarotino (1988), a estrutura mental é biológica e permitiria a capacidade em adquirir o conhecimento, implicando em lógica. Assim, Piaget não possuía preocupação com causas da ocorrência do conhecimento, mas o processo de construção. Os objetivos da Epistemologia Genética seriam identificar as raízes das diversas formas de o ser humano desenvolver o seu conhecimento, desde as formas mais básicas, passando pelos níveis do seu desenvolvimento, até a identificação de como ocorre o conhecimento científico (PIAGET, 1978). Característica marcante da teoria é a interdisciplinaridade, ou seja, a ideia de que o desenvolvimento necessita de conhecimento de variadas formas e da sua interligação.

Os conceitos centrais na teoria de Epistemologia Genética são os de equilibração, assimilação e acomodação dos objetos com os quais os seres humanos interagem para conhecê-los, processos indissociáveis e dinâmicos, sendo que o sujeito possui acomodações e assimilações prévias. Eles ocorrem na ação do sujeito sobre o 
que está sendo conhecido, chamado de objeto. A incorporação é tratada pelo conceito da assimilação, que pode ser entendida pelo ingresso de um elemento exterior (objeto a ser conhecido) em um esquema sensório-motor ou conceitual do sujeito e de um esquema em um sistema. A acomodação é a modificação dos esquemas da assimilação sofrendo as influências do meio - exterior - aos quais eles estão expostos (PIAGET, 1987).

Um dos desafios da pedagogia, sob a perspectiva construtivista, é o de levar em conta as construções cognitivas prévias do estudante (conhecimentos prévios). Para se obter uma interação de qualidade, é necessário que o sujeito ativo assimile efetivamente o que está à sua disposição e também acomode efetivamente. "Não há regulagem do meio interno sem assimilação, isto é, sem perturbação provocada pelo meio externo. Reciprocamente, não há assimilação sem um meio interno devidamente regulado, capaz de assimilar a novidade que se apresenta" (BECKER, 2001, p. 83).

\subsection{Modelos Educacionais Construtivistas}

As ideias construtivistas, sobretudo as ideias às quais a pesquisa se baseia referentes à Epistemologia Genética de Piaget - são ideias que apresentam como se dá o conhecimento humano. Não são necessariamente uma indicação de como deveria ser a educação. Feita a observação, é inegável que as ideias construtivistas possuem uma aplicação pedagógica, mas Macedo (1994) enfatiza que, para isto, é necessário fazer uma transformação da teoria.

Macedo (1994 p. 50) alerta para as diferenças apresentadas acima e sugere que "a aplicação pedagógica da obra de Piaget requer cuidados, muitas vezes por nós ignorados". Isto porque a aplicação desta teoria, tão complexa, não é direta e implica uma mudança de referencial, transformações e a continuidade necessária para que se possa aplicá-la. Nesta pesquisa, utilizou-se o conceito de "modelo", que trata-se de uma representação do real, de forma limitada, que apoia a atividade científica, educacional e informacional, através de comparação, simulação, compreensão de fenômenos e elaboração de métodos que usem seus elementos. Behar, Passerino e Bernardi (2007) relatam que o conceito de modelo não pode ser confundido com o de teoria, pois, embora os modelos se baseiem em teorias, são frutos de interpretação e uso limitado.

Procurou-se entender alguns modelos que são denominados como construtivistas. Com suporte no exposto acima, chamou-os de "modelos educacionais baseados no construtivismo". Apresenta-se, a seguir, um breve panorama da aplicação de modelos de ensino e de aprendizagem baseados no construtivismo.

a. Design Instrucional - surgiu na Segunda Guerra Mundial, para fins militares. Gagné (1962) compilou, em livro, as ideias de um sistema de instrução. Em Administração, foi apresentada uma Simulação de Mondadori (2006) e Mondadori e Santos (2006), sob o tema empreendedorismo. Propõe a organização de problemas significativos, contextos autênticos e resolução dos problemas, sendo baseado em atividades. Vincula as atividades a um problema central, apoio para a resolução dos problemas, por especialistas, diferentes visões, utilização de conhecimentos prévios e a participação (SEEL; DIJKSTRA, 2004).

b. Cognição Situada - surgiu com base na teoria construtivista de Leontiev e Vygotsky. Possui derivações, como a cognitive apprenticeship. Trata-se de uma aprendizagem baseada em uma situação contextualizada, com atividades relacionadas a contextos, através da colaboração e com influência social. Há a construção do conhecimento social e cultural e o estudante assume papel ativo.

c. Instrução Ancorada - criada pelo Cognition and Technology Group at Vanderbilt, abordagem baseada no Design Instrucional, apresenta situações problemáticas ancorada em contextos, em que os problemas e atividades a devem ser resolvidas. Apresenta múltiplas perspectivas sobre o contexto e âncoras através de um 
desafio central e desafios relacionados a ele. $\mathrm{O}$ estudante deve entender porque, quando e como utilizar conceitos.

d. Aprendizagem Vivencial - e laborada a partir das ideias de Kolb e Kolb (2005), baseado nas teorias construtivistas, como as de Dewey, Lewin, Piaget e Vygotsky. A aprendizagem ocorre pela vivência em processos em que é necessário o engajamento do estudante e o feedback de seus esforços. Parte-se das crenças e ideias pré-concebidas relacionada a um contexto, com a adaptação ao mundo a partir da resolução de conflitos. As interações entre o indivíduo e o ambiente em que está inserido e a socialização e conhecimento construído são essenciais nesse modelo.

e. Problem Based Learning (PBL) - a aprendizagem baseada em problemas surgiu na área de medicina norte-americana, na década de 1960. Possui diversas aplicações no Canadá, também na área médica. $\mathrm{O}$ estudante está no centro do processo de aprendizagem e há a aplicação de problemas em situações semelhantes às reais, nos quais as diferentes áreas do conhecimento devem ser utilizadas. Valoriza-se a integração entre estudantes, com o objetivo de resolver os problemas do dia-a-dia, tratados com uma natureza holística, prática e colaborativa (JONASSEN; HUNG, 2015). Guedes et al. (2015), realizaram uma avaliação dessa estratégia na área de Administração, relatando que ela aproxima estudantes e professores, possibilitando o desenvolvimento de senso crítico e a melhoria dos trabalhos em equipe, além de expandir a visão sobre os problemas empresariais, o raciocínio e a criatividade.

\section{Método}

A pesquisa teve natureza qualitativa e exploratória objetivando entender in loco, como ocorre a construção do conhecimento pelo estudante, em um contexto real de ensino da área de Administração. $\mathrm{Na}$ área de Administração, o número de estudos relacionando esta teoria e o ensino ainda é limitado. Em relação à característica qualitativa, a pesquisa apresenta o que Denzin e Lincoln (2006) pressupõem: uma atividade situada que localiza o observador e o objeto que está sendo observado. O observador é o pesquisador, que atua como docente, e o objeto que está sendo observado é composto pelo ensino de Administração e pela aprendizagem do estudante.

$\mathrm{O}$ estudo foi realizado no ambiente de aprendizagem dos cursos técnicos e de graduação tecnológica na área de Administração de uma Instituição Federal de Ensino. A aplicação no ensino presencial foi adotada para que se pudesse ter uma visão do aprendizado dos estudantes, a partir do seu ambiente de aprendizagem. Por se participar ativamente do processo de coleta e análise dos dados, foi necessário elaborar um método para a aplicação da pesquisa (pesquisa social) e uma estrutura para a coleta e a análise dos dados. Utilizou-se o método da "pesquisa-ação" (THIOLLENT, 1997).

Foi elaborado um modelo para o Ensino de Administração, composto por um ambiente de aprendizagem e por uma metodologia de ensino, com a sua efetiva aplicação prática em cursos da área de Administração. A partir da sua utilização em situações reais de ensino que o modelo foi avaliado pelos estudantes e pelo pesquisador, analisando-se os aspectos teóricos que serviram para o embasamento de sua construção, tendo em vista a obtenção de uma validade teórica e prática.

A pesquisa foi executada em quatro fases, descritas a seguir: Fase 1 Exploratória: realização de uma análise das atividades de ensino atuais. Foi realizado um levantamento teórico inicial, realizou-se a definição dos elementos da teoria construtivista que seriam utilizados no modelo e foi elaborado e aplicado um questionário de diagnóstico nas disciplinas em que a pesquisa seria realizada; Fase 2 Principal: tratou do planejamento das ações, após ser concluído o diagnóstico. Foram definidas as ações que seriam realizadas, o contexto da pesquisa (disciplinas, atores e 
Instituição), o modo pelo qual o modelo seria elaborado, os requisitos básicos do modelo e o cronograma das atividades que seriam realizadas. Depois disso, partiu-se para a elaboração do modelo construtivista para o Ensino de Administração. $O$ modelo foi utilizado em um estudo-piloto, para se identificar a necessidade de alterações nos materiais pedagógicos; Fase 3 -Ação: realizou-se estudo-piloto da utilização do modelo. As ações efetivas da pesquisa foram a utilização do modelo em situações de ensino, modificando-se completamente a forma com que os conteúdos eram ensinados e aprendidos. Após algumas modificações no modelo, o mesmo foi utilizado nas disciplinas em que se realizou a pesquisa, sendo que três turmas diferentes o utilizaram em cada semestre; Fase 4 -Avaliação do Modelo: a avaliação do modelo envolveu a análise e a avaliação das consequências da ação, a observação e a direção de novas ações, além do resgate do conhecimento produzido no decorrer do processo. A coleta dos dados foi realizada por intermédio de entrevistas semiestruturadas, pela análise de documentos de autoavaliação e pela observação do pesquisador.

\section{Análise de Dados}

\subsection{Diagnóstico}

A primeira atividade realizada em relação à análise dos dados foi uma análise de como ocorre, de forma geral, o ensino de Administração. Ele se dividiu em dois pontos principais: o primeiro enfatiza o ensino desta área ainda está baseado nos modelos tradicionais, centralizados na figura do professor, e em métodos, como: aulas expositivas; recomendação de leituras; repasse de conceitos; e realização de provas conceituais (MONDADORI, 2006; MONDADORI; SANTOS, 2006).

$\mathrm{O}$ segundo ponto analisado através de um questionário respondido pelos estudantes investigou como se dava o ensino na instituição que se realizou a pesquisa. A análise dos aspectos evidenciados pelos estudantes revelou, de forma resumida, que:

a) o processo estava centrado na figura do professor e os estudantes ficavam passivos, recebendo o conteúdo e anotando ou lendo conceitos;

b) as aulas eram basicamente exposições de conceitos, com realização de exercícios e trabalhos realizados sobre os conceitos expostos;

c) as avaliações eram relacionadas aos conceitos previamente repassados pelo professor, e se baseavam em produto final, não no processo;

d) as atividades dos estudantes eram, basicamente, tidas como complementares às aulas expositivas, tais como pesquisas de conceitos, resolução de exercícios e trabalhos em relação ao conteúdo repassado;

e) apesar da abertura ao debate e exposição dos estudantes, os diálogos eram um tanto limitados, considerando apenas os conceitos expostos pelo professor;

f) a disposição física dos estudantes não favorecia a interação entre eles;

g) as atividades práticas, apesar de limitadas, incentivaram o diálogo.

\subsection{Modelo Construtivista para o Ensino de Administração}

A partir da análise do diagnóstico e dos aspectos construtivistas necessários a um modelo de ensino, foi necessário transformar também o ambiente em que ocorria o processo, modificando-se a interação entre os estudantes, o material pedagógico e o próprio papel do professor. Os elementos teóricos formaram um quadro de referência e foram incluídos no modelo, a partir das escolhas do pesquisador: ação, significação, conflitos cognitivos, conhecimentos prévios, socialização, avaliação, autonomia e interdisciplinaridade. $\mathrm{O}$ modelo proposto foi baseado no quadro de referência e em dois elementos:

a) metodologia de ensino - elaborada a partir do quadro de referência, procurou centralizar o processo de ensino na pessoa do estudante, ações, interação e resolução de 
problemas reais, utilizando-se informações não estruturadas. A ideia era deixar de lado a forma tradicional, expositiva e fazer o estudante entender conceitos em discussão a partir da sua ação, decisões, de sua experiência e dos seus conhecimentos previamente construídos. A complexidade dos problemas empresariais relacionados aos contextos das empresas envolvidas nas questões e a fatores que pudessem ser interessantes para o estudante foram incluídas.

As disciplinas foram organizadas de forma a representar a complexidade da área de Administração e a fazer com que os estudantes utilizassem seus conhecimentos prévios, relacionando entre si as diversas facetas da área da Administração em problemas reais. A divisão dos conteúdos foi realizada a partir do que se chamou de Contextos de Aprendizagem e Situações de Aprendizagem. Compreendeu um conjunto de conhecimentos que seriam necessários para que o estudante pudesse entender os conceitos relacionados a uma área. Foram elaborados dois contextos diversos: o Teoria Geral da Administração e Planejamento Estratégico. As Situações de Aprendizagem (SA) compreenderam um conjunto de problemas, dividindo cada um dos dois contextos em atividades que deveriam ser cumpridas pelos estudantes. As SA foram baseadas em pesquisas bibliográficas minuciosas, sempre com o objetivo de levar o estudante a confrontar aspectos teóricos com aspectos práticos, para a resolução de problemas na área de Administração;

b) ambiente de aprendizagem - o segundo elemento foi uma modificação no ambiente de aprendizagem que era apresentado. A modificação que se realizou foi em relação ao arranjo físico e à formação dos grupos de trabalho. A adoção de um arranjo físico que permitisse melhorar a interação entre os estudantes e a sua proximidade favoreceria o ambiente de aprendizagem e seria mais um fator para apoiar a construção do conhecimento. Adotou-se um novo layout nas salas de aula, no qual os estudantes trabalhavam em grupo, como em uma organização, em "ilhas", em que trabalhavam como consultores para resolver os problemas de empresas.

Em relação aos aspectos tecnológicos, o modelo foi apoiado por um sistema de informação, chamado Moodle (Modular Object-Oriented Dynamic Learning Environment) e um conjunto de objetos de aprendizagem construídos especificamente para o modelo. No ambiente elaborado, o estudante constrói o seu conhecimento através de situações representadas pelos Contextos e pelas SA. Para que o estudante possa realizar uma abordagem efetiva, as situações foram modeladas de forma a tornar explícitas as relações entre os domínios de conhecimento e a prática.

\subsection{Análise do Uso do Modelo}

O modelo foi utilizado por 163 estudantes dos cursos de administração da instituição pesquisada, nas disciplinas de Teoria Geral da Administração, no seu primeiro semestre, e de Planejamento Estratégico, no último semestre. Cada turma possuía 30 estudantes, em seu início. Algumas turmas tiveram algumas desistências ou aproveitamento de disciplinas, fazendo com que o número total de estudantes fosse reduzido para de 180 para 163.

Em relação ao perfil dos estudantes, realizou-se a análise do grupo como um todo. Cerca de $70 \%$ dos estudantes possuía até 25 anos. As idades variavam de 17 a 53 anos de idade, sendo a média de idade de 23,7 anos, com desvio padrão de 5,7. O gênero predominante era o feminino, com aproximadamente $62 \%$ dos estudantes. A grande maioria dos estudantes era trabalhadora, representando $91,5 \%$ do total de estudantes. A média de tempo de trabalho daqueles estudantes era de aproximadamente seis anos por pessoa. Daquela maioria de estudantes trabalhadores, o setor industrial era que os empregava com maior frequência, com 38,57\% dos trabalhadores, seguido dos setores comercial, com $33,57 \%$ e do de serviços, com $27,86 \%$ do total. 
O modelo foi utilizado nos dois semestres que se seguiram o estudo-piloto. Apesar da sua complexidade e da necessidade de uma mudança de paradigma, as turmas que tiveram acesso ao modelo sentiram-se confortáveis em relação à realização das atividades, ainda que, inicialmente, não percebessem se ele seria realmente efetivo. Apresenta-se, a seguir, a avaliação do modelo, realizada a partir de entrevistas com os estudantes que participaram da pesquisa. As entrevistas foram transcritas e resumidas, neste trabalho, sendo apresentadas na Tabela 1. Foi realizado um resumo da análise das respostas ao protocolo de pesquisa e identificou-se itens a serem melhorados no modelo.

Tabela 1: Análise do Modelo e dos Itens a Melhorar.

\begin{tabular}{|c|c|c|c|}
\hline Elemento & $\begin{array}{c}\text { Questão } \\
\text { (Protocolo) }\end{array}$ & Análise geral & Itens a melhorar \\
\hline \multirow{5}{*}{ Ação } & $\begin{array}{l}\text { Tipo de } \\
\text { práticas } \\
\text { utilizadas }\end{array}$ & $\begin{array}{l}\text { Estudantes perceberam a realização de atividades, } \\
\text { pesquisas bibliográficas e acesso a materiais } \\
\text { pedagógicos; percebeu-se resolução de problemas, } \\
\text { tomada de decisão e a necessidade de realizar pesquisas. }\end{array}$ & $\begin{array}{l}\text { Materiais necessitam } \\
\text { melhorias, em relação à } \\
\text { proposição das } \\
\text { atividades, com ações. }\end{array}$ \\
\hline & $\begin{array}{l}\text { Interação } \\
\text { com } \\
\text { materiais } \\
\text { pedagógicos }\end{array}$ & $\begin{array}{l}\text { Interação facilitada com materiais disponibilizados em } \\
\text { tempo hábil; necessidade de ler os materiais antes de } \\
\text { iniciarem as atividades; leitura antecipada facilita } \\
\text { discussões. Materiais forneciam informações suficientes. }\end{array}$ & $\begin{array}{l}\text { Alguns materiais } \\
\text { repetitivos, necessitado } \\
\text { revisar e antecipar a } \\
\text { disponibilidade. }\end{array}$ \\
\hline & $\begin{array}{l}\text { Tomada de } \\
\text { decisões }\end{array}$ & $\begin{array}{l}\text { Estudantes se sentiram confusos no início, pois esperavam } \\
\text { resposta "única" para problemas; quando perceberam que } \\
\text { a decisão não era a correta, ficaram um tanto frustrados; o } \\
\text { erro poderia servir para o aprendizado, sendo importante } \\
\text { para entender o impacto das decisões. }\end{array}$ & $\begin{array}{l}\text { Decisões e erros } \\
\text { preocupam estudantes; } \\
\text { melhorar revisão dos } \\
\text { erros entre as SA. }\end{array}$ \\
\hline & $\begin{array}{l}\text { Uso real dos } \\
\text { conhecimen } \\
\text { tos }\end{array}$ & $\begin{array}{l}\text { Os estudantes relataram que as SA apresentaram } \\
\text { exemplos reais, favorecendo a relação da teoria com a } \\
\text { prática; houve a relação das ações das SA com o mundo } \\
\text { real; percebeu-se a aplicabilidade prática dos conceitos. }\end{array}$ & $\begin{array}{l}\text { Incluir mais } \\
\text { ferramentas que os } \\
\text { estudantes possam } \\
\text { utilizá-las no dia-a-dia. }\end{array}$ \\
\hline & $\begin{array}{l}\text { Assimilação } \\
\text { de novos } \\
\text { conceitos }\end{array}$ & $\begin{array}{l}\text { Novos conceitos eram apresentados a partir das } \\
\text { atividades, circundavam as decisões e atividades; ocorria } \\
\text { a assimilação de novos conceitos, com a necessidade de } \\
\text { resolver o problema, em que era necessário pesquisar no } \\
\text { material pedagógico, em bibliografias. }\end{array}$ & $\begin{array}{l}\text { Incluir questões } \\
\text { conceituais para a } \\
\text { percepção da relação } \\
\text { conceitual e prática. }\end{array}$ \\
\hline \multirow{5}{*}{$\begin{array}{l}\text { Significa- } \\
\text { ção }\end{array}$} & $\begin{array}{l}\text { Exigências } \\
\text { das SA }\end{array}$ & $\begin{array}{l}\text { Havia a necessidade de reflexão e da relação com a } \\
\text { prática para resolução dos problemas; necessário pensar } \\
\text { praticamente e relacionar as situações com fatores do dia- } \\
\text { a-dia empresarial; necessidade de atribuir significado às } \\
\text { atividades, através da reflexão sobre ações e problemas. }\end{array}$ & $\begin{array}{l}\text { Não foram } \\
\text { identificados. }\end{array}$ \\
\hline & $\begin{array}{l}\text { Reflexão em } \\
\text { relação aos } \\
\text { problemas }\end{array}$ & $\begin{array}{l}\text { Era necessário fazer relação entre problemas e contextos } \\
\text { empresariais; com a prática, as atividades de reflexão } \\
\text { ficaram facilitadas; materiais pedagógicos favoreciam a } \\
\text { contextualização; problemas reais favorecem o processo. }\end{array}$ & $\begin{array}{l}\text { As reflexões em } \\
\text { relação à realidade } \\
\text { ficaram complexas em } \\
\text { algumas SA. }\end{array}$ \\
\hline & $\begin{array}{l}\text { Sentido das } \\
\text { Atividades }\end{array}$ & $\begin{array}{l}\text { Foi ressaltada a possibilidade de relação com a realidade } \\
\text { das empresas; estudantes procuravam entender os } \\
\text { problemas que, provavelmente, enfrentariam no futuro; } \\
\text { sentido aplicação prática nas empresas, em situações de } \\
\text { trabalho. }\end{array}$ & $\begin{array}{l}\text { Enfatizar relações } \\
\text { práticas e uso da } \\
\text { experiência; algumas } \\
\text { confusões nas relações } \\
\text { teoria/prática. }\end{array}$ \\
\hline & $\begin{array}{l}\text { Entendimen } \\
\text { to dos } \\
\text { conceitos }\end{array}$ & $\begin{array}{l}\text { Estudantes relataram que o entendimento foi facilitado } \\
\text { pelos contextos próximos de sua cultura e pela } \\
\text { possibilidade de revisão, que era realizado pela correção } \\
\text { dos relatórios, orientações e seminários; conflitos } \\
\text { cognitivos facilitaram entendimento dos conceitos. }\end{array}$ & $\begin{array}{l}\text { Explorar mais conflitos } \\
\text { cognitivos através de } \\
\text { provocações e } \\
\text { contrapontos. }\end{array}$ \\
\hline & $\begin{array}{l}\text { Reflexão } \\
\text { sobre os } \\
\text { problemas }\end{array}$ & $\begin{array}{l}\text { A reflexão geralmente iniciava com a leitura dos } \\
\text { documentos, e também era exercitada nas discussões em } \\
\text { grupo; as discussões incentivavam a reflexão, pois os } \\
\text { pontos de vista dos colegas eram expostos serviam como } \\
\text { contraponto; seminários serviam como reflexão. }\end{array}$ & $\begin{array}{l}\text { Não foram } \\
\text { identificados. }\end{array}$ \\
\hline $\begin{array}{l}\text { Conflitos } \\
\text { cogniti- } \\
\text { vos }\end{array}$ & $\begin{array}{l}\text { Necessidade } \\
\text { de revisão } \\
\text { de conceitos }\end{array}$ & $\begin{array}{l}\text { Uma SA seguinte tratava dos conceitos das SA anteriores, } \\
\text { obrigando a revisão; era necessário rever e refletir sobre } \\
\text { resultados alcançados; seminários exigiam a revisão, por } \\
\text { meio de questionamentos e argumentações; era necessário } \\
\text { rever respostas e conceitos pesquisados. }\end{array}$ & $\begin{array}{l}\text { Não foram } \\
\text { identificados. }\end{array}$ \\
\hline
\end{tabular}




\begin{tabular}{|c|c|c|c|}
\hline & $\begin{array}{l}\text { Como } \\
\text { ocorreu o } \\
\text { processo de } \\
\text { revisão }\end{array}$ & $\begin{array}{l}\text { Era necessário que fosse feita uma revisão, especialmente } \\
\text { através dos relatórios, os quais eram avaliados e } \\
\text { retornados; os seminários sempre geravam necessidade } \\
\text { de revisões, pela exposição das experiências dos colegas } \\
\text { e pelas explanações e questionamentos do professor. }\end{array}$ & $\begin{array}{l}\text { O processo de revisão } \\
\text { pode melhorar, com } \\
\text { tempo maior para } \\
\text { seminários e tratamento } \\
\text { dos relatórios. }\end{array}$ \\
\hline \multirow{3}{*}{$\begin{array}{l}\text { Conheci- } \\
\text { mentos } \\
\text { prévios }\end{array}$} & $\begin{array}{l}\text { Avaliação } \\
\text { prévia dos } \\
\text { conhecimen } \\
\text { tos dos } \\
\text { estudantes }\end{array}$ & $\begin{array}{l}\text { Avaliações eram realizadas no início de cada SA, através } \\
\text { de questionamentos em relatórios; as SA seguintes eram } \\
\text { orientadas de acordo com esses resultados, permitindo } \\
\text { identificar estudantes que já possuíam conhecimentos; } \\
\text { estudantes não percebem avaliações prévias. }\end{array}$ & $\begin{array}{l}\text { Item parece ter passado } \\
\text { despercebido; seria } \\
\text { necessário elaborar } \\
\text { uma nova forma de } \\
\text { avaliação prévia. }\end{array}$ \\
\hline & $\begin{array}{l}\text { Utilização } \\
\qquad \text { do } \\
\text { conhecimen } \\
\text { to prévio }\end{array}$ & $\begin{array}{l}\text { Os estudantes ter sido incentivados a utilizar concepções } \\
\text { prévias na resolução dos problemas; as situações práticas } \\
\text { exigiriam uso da sua "bagagem" na resolução dos } \\
\text { problemas; o conhecimento dos colegas também podia } \\
\text { ser um fator importante para o aprendizado. }\end{array}$ & $\begin{array}{l}\text { Não foram } \\
\text { identificados. }\end{array}$ \\
\hline & $\begin{array}{l}\text { Utilização } \\
\text { da } \\
\text { experiência }\end{array}$ & $\begin{array}{l}\text { A experiência dos estudantes foi utilizada em sua } \\
\text { associação com situações reais que eles tivessem vivido } \\
\text { e, também, estimulando a que eles se colocassem no } \\
\text { lugar das pessoas que estavam vivendo tais situações. }\end{array}$ & $\begin{array}{l}\text { Não foram } \\
\text { identificados. }\end{array}$ \\
\hline \multirow{3}{*}{$\begin{array}{l}\text { Socializa- } \\
\text { ção }\end{array}$} & $\begin{array}{c}\text { Interação } \\
\text { com colegas } \\
\text { e professor }\end{array}$ & $\begin{array}{l}\text { Discussões eram produtivas, apesar de ocasionais } \\
\text { discordâncias; em alguns casos, não se chegava a um } \\
\text { consenso a partir da interação; a relação entre os grupos } \\
\text { ocorria sob a orientação do professor, ao longo das SA. }\end{array}$ & $\begin{array}{l}\text { Realizar uma } \\
\text { explicação mais } \\
\text { detalhada dos } \\
\text { problemas. }\end{array}$ \\
\hline & $\begin{array}{l}\text { Incentivo à } \\
\text { discussão e } \\
\text { debates }\end{array}$ & $\begin{array}{l}\text { Discussão e debate eram fatores primordiais, pois os } \\
\text { trabalhos foram realizados em grupo; os debates eram } \\
\text { importantes porque as atividades exigiram diferentes } \\
\text { tarefas em grupo para que se chegasse a uma decisão; em } \\
\text { alguns casos, era atingido um consenso; porém, na } \\
\text { maioria das vezes, isto não acontecia. }\end{array}$ & $\begin{array}{l}\text { Não foram } \\
\text { identificados. }\end{array}$ \\
\hline & $\begin{array}{l}\text { Incentivo à } \\
\text { troca de } \\
\text { ideias com o } \\
\text { professor }\end{array}$ & $\begin{array}{l}\text { Interação ocorria quando um grupo tinha alguma dúvida } \\
\text { ou desejava esclarecimento específico; o professor era } \\
\text { chamado e havia diálogos específicos atividades; os } \\
\text { grupos ou os estudantes, contatavam o professor e } \\
\text { conversavam, sendo a conversa em relação ao relatório } \\
\text { elaborado ou a temas das argumentações. }\end{array}$ & $\begin{array}{l}\text { Não foram } \\
\text { identificados. }\end{array}$ \\
\hline \multirow{2}{*}{ Avaliação } & $\begin{array}{l}\text { Autoavalia- } \\
\text { ção }\end{array}$ & $\begin{array}{l}\text { Havia } 2 \text { oportunidades: 1) escrita, durante os trabalhos, } \\
\text { sendo que era necessário realizar uma reflexão sobre o } \\
\text { aprendizado; 2) nos seminários, momento em que os } \\
\text { estudantes poderiam revisar seu aprendizado, rever novos } \\
\text { conceitos e decidir quanto ao aprofundamento. As } \\
\text { escritas foram mais perceptíveis. }\end{array}$ & $\begin{array}{l}\text { Seria necessário } \\
\text { melhorar a avaliação do } \\
\text { aprendizado do } \\
\text { estudante sobre todo o } \\
\text { processo de } \\
\text { aprendizagem. }\end{array}$ \\
\hline & $\begin{array}{l}\text { Avaliações } \\
\text { do } \\
\text { aprendizado }\end{array}$ & $\begin{array}{l}\text { Em todas as atividades realizadas foram avaliadas através } \\
\text { dos relatórios produzidos pelas equipes. As avaliações } \\
\text { individuais (provas) possuíam questões ligadas à prática } \\
\text { empresarial e à reflexão sobre os conceitos; os } \\
\text { entrevistados relataram que as avaliações eram } \\
\text { complexas, exigindo reflexão aprofundada. }\end{array}$ & $\begin{array}{l}\text { Não foram } \\
\text { identificados. }\end{array}$ \\
\hline \multirow{3}{*}{$\begin{array}{l}\text { Autono- } \\
\text { mia }\end{array}$} & $\begin{array}{l}\text { Autonomia } \\
\text { do estudante }\end{array}$ & $\begin{array}{l}\text { Existiam regras a serem seguidas, mas liberdade no } \\
\text { acesso aos materiais; era necessário "partir em busca" das } \\
\text { respostas; a resolução prática fazia com que o estudante } \\
\text { tivesse que construir respostas, elaborando relatórios e } \\
\text { incrementando o seu conhecimento de forma dialogada e } \\
\text { em seu ritmo. }\end{array}$ & $\begin{array}{l}\text { Não foram } \\
\text { identificados. }\end{array}$ \\
\hline & $\begin{array}{l}\text { Ritmo de } \\
\text { aprendizage } \\
\mathrm{m}\end{array}$ & $\begin{array}{l}\text { Os estudantes relataram que as atividades geralmente } \\
\text { seguiam o ritmo da turma como um todo e não o ritmo } \\
\text { individual; este ritmo individual somente era observado } \\
\text { na possibilidade de ordem de leitura dos documentos. }\end{array}$ & $\begin{array}{l}\text { O ritmo individual de } \\
\text { aprendizagem deverá } \\
\text { ter um tratamento mais } \\
\text { detalhado no futuro. }\end{array}$ \\
\hline & $\begin{array}{l}\text { Negociação } \\
\text { de metas e } \\
\text { objetivos }\end{array}$ & $\begin{array}{l}\text { Os objetivos geralmente já estavam pré-definidos no } \\
\text { documento de apresentação das SA; as negociações } \\
\text { estavam mais relacionadas aos prazos para a resolução e } \\
\text { entrega das atividades. }\end{array}$ & $\begin{array}{l}\text { Os objetivos de } \\
\text { aprendizagem devem } \\
\text { ser negociados antes } \\
\text { das SA. }\end{array}$ \\
\hline $\begin{array}{l}\text { Interdis- } \\
\text { ciplinari- } \\
\text { dade }\end{array}$ & $\begin{array}{l}\text { Relação } \\
\text { com outras } \\
\text { áreas do } \\
\text { conhecimen } \\
\text { to }\end{array}$ & $\begin{array}{l}\text { Havia a interligação das atividades e dos problemas com } \\
\text { o seu contexto; os problemas representados sempre } \\
\text { possuíam relação com outros aspectos da realidade; as } \\
\text { atividades envolviam uma relação ampla com outras } \\
\text { áreas do conhecimento, ligados à época do seu }\end{array}$ & $\begin{array}{l}\text { Seria necessário } \\
\text { ampliar as relações } \\
\text { entre as variadas áreas } \\
\text { do conhecimento. }\end{array}$ \\
\hline
\end{tabular}




\begin{tabular}{l|l|l|l}
\hline & acontecimento e questões econômicas, políticas e sociais. & \\
\cline { 2 - 5 } & $\begin{array}{l}\text { Busca de } \\
\text { conhecimen } \\
\text { tos além do } \\
\text { conteúdo } \\
\text { programátic } \\
\text { o. }\end{array}$ & $\begin{array}{l}\text { Sempre era necessário que se pesquisasse para resolver os } \\
\text { problemas e relacionar isso ao contexto empresarial; os } \\
\text { problemas exigiam a pesquisa, dirigida aos problemas e } \\
\text { prática; não havia um incentivo à pesquisa em outras } \\
\text { áreas. }\end{array}$ & $\begin{array}{l}\text { Incluir relações mais e problemas de } \\
\text { outras áreas do } \\
\text { conhecimento. }\end{array}$ \\
$\begin{array}{l}\text { Diversas } \\
\text { alternativas } \\
\text { para a } \\
\text { solução dos } \\
\text { problemas. }\end{array}$ & $\begin{array}{l}\text { Era necessário negociar e elaborar, junto ao grupo, } \\
\text { alternativas para a resolução dos problemas; a solução } \\
\text { mais adequada seria escolhida em conjunto; o número de } \\
\text { alternativas ficava a cargo das equipes, não existindo um } \\
\text { número mínimo exigido. }\end{array}$ & $\begin{array}{l}\text { Não foram } \\
\text { identificados. }\end{array}$ \\
\hline
\end{tabular}

Fonte: Elaborada pelo autor.

A utilização do modelo proposto neste trabalho em situações reais de ensino permitiu a exposição dos estudantes a experiências e o confronto de suas concepções prévias com situações próximas da realidade empresarial, além de expor os estudantes a experimentos relativos à tomada de decisões e à resolução de problemas empresariais especificamente elaborados para o modelo. A tecnologia, os objetos de aprendizagem e a mudança do ambiente físico, facilitaram o processo de construção do conhecimento.

\section{CONSIDERAÇÕES FINAIS}

A inovação do ensino em Administração, com a elaboração de novos métodos de ensino e ambientes de aprendizagem apoiados pela tecnologia, ultrapassa os métodos convencionais, de repasse dos conteúdos. Independentemente da discussão da possibilidade de modificação do paradigma atual da educação em Administração, a proposta inicial era apresentar uma forma inovadora de educar, com um novo modelo de ensino, provocando, assim, nessa área, uma reflexão sobre o assunto.

O estudo possui como limitações a impossibilidade generalização das conclusões, por se tratar de um estudo qualitativo, realizado em uma única instituição, o referencial teórico apresentado, que apresenta-se reduzido. Há uma amplitude conceitual em relação ao construtivismo, que possui inúmeros autores e diferentes correntes, mas no estudo não foi possível utilizar todos os autores da área por limitação de tempo. Outra limitação refere-se ao fato de o estudo ser exploratório, com o intuito de aprofundamento em relação ao tema que foi apresentado no referencial teórico. $\mathrm{O}$ modelo necessita ser aplicado em outros contextos e em outras disciplinas e aplicação foi limitada a duas disciplinas da área de administração.

Considera-se que o estudo permitiu a abertura de uma nova oportunidade para pesquisas e para o próprio ensino de Administração. A transformação qualitativa da aprendizagem, seja na educação a distância, seja no ensino presencial, não pode ocorrer somente pela transferência do ensino convencional para novos modelos interativos. Caso isso ocorra, os métodos tradicionais de ensino em Administração continuarão com as suas limitações como a linearidade, a fragmentação e a distância com a prática. Por fim, entende-se que é importante que sejam apresentadas inovações educacionais na área, através dos métodos ativos de aprendizagem, com a centralização do processo de ensino e aprendizagem na figura do estudantes, permitindo a construção de conhecimentos aprofundada sobre os assuntos que fazem parte do processo.

\section{REFERÊNCIAS}

BECKER, F. Educação e construção do conhecimento. Porto Alegre: Artmed, 2001. BEHAR, P. A.; PASSERINO, L.; BERNARDI, M.. Modelos pedagógicos para educação a distância: pressupostos teóricos para a construção de objetos de aprendizagem. Novas Tecnologias na Educação. Porto Alegre, v. 5, n. 2, p. 2538, dez, 2007. 
DENZIN, N. K.; LINCOLN, Y. S. A disciplina e a prática da pesquisa qualitativa. In: (Orgs.). O planejamento da pesquisa qualitativa: teorias e abordagens. Porto Alegre: Artmed, 2006.

FAINHOLO, B. Perspectiva da educação a distância no campo da educação formal e no desenvolvimento social Argentino e Latino-americano. Revista Tecnologia Educacional, Rio de Janeiro, v. 23, n. 118, p. 12-20, maio/jun, 1994.

GAGNÉ, R. M. Princípios essenciais da aprendizagem para o ensino. Porto Alegre: Globo, 1980.

GIJBELS, D. et al. New learning environments and constructivism: the students' perspective. Instructional Science, Amsterdam, v. 34, n. 1, p. 213-226, 2006.

GUEDES, K. L. et al,. A Avaliação de Estudandes e Professores de dministração sobre a Experiência com a Aprendizagem Baseada em Problemas. Administração: Ensino e Pesquisa. V. 16 No 1 P. 71-100, Jan-Mar, 2015.

KOLB, A. I.; KOLB, D. Learning Styles and Learning Spaces: Enhancing experiential learning in higher education. Academy of management learning and education, New York, v. 4, n. 2, p. 193-212, 2005.

JONASSEN, D. H.; HUNG, W. All Problems are Not Equal: Implications for Problembased Learning. Essential Readings in Problem-Based Learning: Exploring and Extending the Legacy of Howard S. Barrows. Purdue UP, 2015. 17-42.

MACEDO, L. Aprender com jogos e situações-problema. Porto Alegre: Artes Médicas Sul, 2000.

. Ensaios construtivistas. São Paulo: Casa do Psicólogo, 1994.

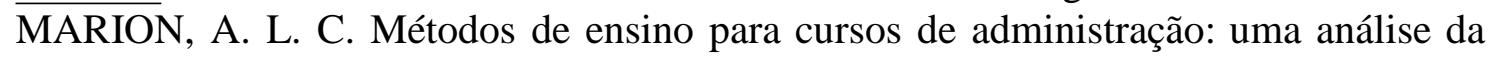
aplicabilidade e eficiência dos métodos. 2007. 125 f. Dissertação (Mestrado em Administração) - Pontifícia Universidade Católica, São Paulo, 2001.

MONDADORI, M. G. Desenvolvimento de um ambiente complexo de aprendizagem baseado em computador aplicado à Administração. 2006. Dissertação (Mestrado em Administração) - Programa de Pós-Graduação em Administração, Escola de Administração, Universidade Federal do rio Grande do Sul, Porto Alegre, 2006.

MONDADORI, M. G.; SANTOS, E. R. Uma proposta de princípios para a construção de ambientes de aprendizagem com orientação construtivista para o ensino em Administração. Novas Tecnologias na Educação, Porto Alegre, v. 4, n. 1, p. 16, 2006.

NEVADO, R. A. Espaços interativos de construção de possíveis: uma nova modalidade de formação de professores. Tese (Doutorado em Educação) - Programa de Pós-Graduação em Informática na Educação, UFRGS, Porto Alegre, 2001.

PIAGET, J. Epistemologia genética. São Paulo: Martins Fontes, 1978.

O nascimento da Inteligência na Criança. 4. ed. Rio de Janeiro: Guanabara, 1987.

RAMOZZI-CHIAROTINO, Z. Psicologia e epistemologia genética de Jean Piaget. São Paulo: Pedagógica e Universitária, 1988.

SEEL, N. M.; DIJKSTRA, S. Curriculum, plans, and process in instructional design: international perspectives. Mahwah: Lawrence Erlbaum Associates, 2004.

SOUZA, E. et al. Métodos e técnicas de ensino e recursos didáticos para o ensino de empreendedorismo em IES brasileiras. In: Anais do ENANPAD, 28. Curitiba. Anais... Curitiba: ANPAD, 2004. 1 CD-ROM.

THIOLLENT, M. Pesquisa-ação nas organizações. São Paulo: Atlas, 1997. 